\title{
The effectiveness of the biodegradation of raw and processed polystyrene by mealworms
}

\author{
Karol Leluk ${ }^{1}$, Beata Hanus-Lorenz ${ }^{1, *}$, Justyna Rybak $^{1}$, and Magdalena Bożek ${ }^{1}$ \\ ${ }^{1}$ Wrocław University of Science and Technology, Department of Environmental Protection, \\ Wybrzeże Wyspiańskiego 27, 50-370 Wrocław, Poland
}

\begin{abstract}
In our studies biodegradation of four variants of polystyrene was performed. We tested: raw material (PS), processed polystyrene (PSr), building insulation material (EPS) and food packaging boxes (PSp). Materials were characterized by means melt flow ratio (MFR), shore hardness and gloss. The biochemical assessment of macromolecules (proteins, lipids and sugars) in the mealworms organisms fed with tested forms of polystyrene allowed us to set how efficient and beneficial the biodegradation of types of polystyrene is. We also evaluated the variability of bacterial community in larval guts by the use of denaturing gradient gel electrophoresis (DGGE) on the bacterial DNA of 16S rRNA genes amplified in polymerase chain reaction (PCR). The results suggest that EPS and PSp polystyrene are the most digestible for T. molitor larvae. The metabolic degradation of polystyrene is probably strictly connected with the changes in biodiversity of gut bacteria.
\end{abstract}

\section{Introduction}

With increasing global consumption and their natural resistance to degradation, plastic materials and their accumulation in the environment is of increasing concern. As a rule, widely used polymer plastics do not undergo degradation process in environment [1]. The huge part of waste plastics is disposed of $(72 \%)$ on a landfill, whereas the remaining part is incinerated or recycled [2]. Since polystyrene is a high molecular weight synthetic hydrophobic polymer, it is not easily biodegradable. In order to simplify and improve its biodegradation rate the addition of starch is usually applied [3]. Although polystyrene is believed to be a non-biodegradable material, it has been proved recently that mealworms, the larvae of Tenebrio molitor Linnaeus L. (Coleoptera: Tenebrionidae) are able to chew and digest styrofoam, a common polystyrene product [4]. The yellow mealworm is commercially available in Poland. Yang et al. [4] confirmed polystyrene biodegradation in

\footnotetext{
*Corresponding author: beata.hanus-lorenz@pwr.edu.pl
} 
the larval gut of this larvae and proved the presence of petroleum based plastic-degrading process in the environment. The studies on biodegradation by mealworms of raw and processed polystyrene have never been conducted.

The aim of our experiment was to compare the effectiveness of biodegradation of four different forms of polystyrene (raw material, processed polystyrene, construction material used for the insulation purposes and food packaging boxes) by mealworms which were fed on all four PS species. In order to better understanding the processes occurring in the investigated materials some analytical techniques were used to fully characterize all four species. In our experiment we based on the mass loss of studied materials as well as lipid, total sugar and carbohydrates contents in larval body. We also evaluated the variability of bacterial community in larval guts by the use of denaturing gradient gel electrophoresis (DGGE) on the bacterial DNA of 16S rRNA gene amplified in polymerase chain reaction (PCR), a commonly used molecular technique for rapid fingerprint analysis of the microbial community. We assessed the changes in biodiversity of gut microorganisms presented in the mealworms fed on polystyrene. The alterations in gut microbial composition are connected to the diet. Serving polystyrene as only food can implicate such changes.

\section{Materials and methods}

\subsection{Materials}

Tenebrio molitor belongs to Tenebrionidae family (Coleoptera, Insecta). The life cycle of T. molitor is of variable length, from 280 to 630 days depending on the temperature and humidity. Larvae hatch after $10-12$ days (at $18-20^{\circ} \mathrm{C}$ ), molt many times, then change into pupa stage and finally after 3-4 months (at ambient temperature) become mature. The length of larvae is about $2.5 \mathrm{~cm}$, whereas adults from 1.25 to $1.8 \mathrm{~cm}$. T. molitor is a pest of grain, flour and food stores. They are typically fed on flour (wheat, oats, maize) supplemented with fresh fruits and vegetables (carrots, potatoes, lettuce) for moisture together with protein sources such as soybean flour, skimmed milk powder or yeast [5]. In our studies larvae of T. molitor were obtained from the inbreeding farm in Lublin (Poland).

Samples of raw polystyrene (PS) used in the study were ordered from joint-stock company Krakchemia S.A. (Poland) under the brand name SYNTHOS PS GP 137. Basic properties of the material are found on the manufacturer's website [6]. Prior to first processing cycle, material was dried in $70^{\circ} \mathrm{C}$ for 3 hours. The second group of material investigated was processed polystyrene (PSr). It was obtained by subsequent processing of the PS by means of extrusion, injection moulding and grinding (in order). The processing cycle was repeated ten times.

The third and the fourth group of material's tested were commercially available. The first one was insulation material - expanded polystyrene (EPS), the second one - packaging material for food products (PSp).

All materials were press moulded into the form of cuboidal plate $(100 \times 100 \times 0,1 \mathrm{~mm})$ prior to physico-mechanical characterisation. PS and PSr were also press moulded before being applied to consumption test, but EPS and PSp were applied without any further processing except cutting down PSp to smaller parts of suitable dimensions. 


\subsection{Methods}

\subsubsection{Experiment design}

\section{Preparation of materials}

Polystyrene was processed using one-screw extruder (HAAKE Rheomex 252), injection moulding machine (BOY 35A) and grinder (Wanner). Processing temperature was set to the values typical for PS thermoplastic processing; according to the manufacturer's note. For extrusion process temperatures on the extruder's zones were as follows: $205^{\circ} \mathrm{C}, 220^{\circ} \mathrm{C}$, $210^{\circ} \mathrm{C}$ and $200^{\circ} \mathrm{C}$ (die zone temperature), whereas for injection moulding temperature ranged $200-250^{\circ} \mathrm{C}$. Injection pressure profile was set to diminishing from $700^{\circ}$ bar down to $550^{\circ}$ bar, cycle time interval was set to $2 \mathrm{~s}$. Press moulding was performed on the laboratory press LabTech LP-20B under the following conditions: process temperature $220^{\circ} \mathrm{C}$, plasticization time $60 \mathrm{~s}$, actual process time $120 \mathrm{~s}$, pressure applied: 50 bar.

Melt flow ratio was estimated using MeltFlow Junior (CEAST) apparatus. Conditions were as follows: load $(2.16 \mathrm{~kg})$, temperature $\left(210^{\circ} \mathrm{C}\right)$, cutting time $(30 \mathrm{~s})$, preheating time $(120 \mathrm{~s})$. Each measurement was repeated at least three times (until the difference between three measured points was no greater than $10 \%)$.

Hardness was measured in Shore D (ShD) for PS and PSr and Shore A (ShA) scale for EPS and PSp samples, by applying $1 \mathrm{~kg}$ load to the tip end.

Gloss was measured at $60^{\circ}$ (semi-gloss surface) using Multi Gloss 268 Plus (Konica Minolta).

For all resulting values an error was estimated as a standard deviation of the mean value and presented on the corresponding figures as error bars.

\section{Mealworms}

T. molitor specimens were divided into 5 groups ( 20 specimens each,) depending on the type of feeding (raw polystyrene PS, processed polystyrene PSr, EPS and PSp and control). We have selected the larvae of the similar mass (from 0.03-0.04g at the beginning of the experiment). The variants used in tests were as follows:

- larvae consuming oatmeal ad libitum (control);

- larvae consuming PS plates;

- larvae consuming PSr plates;

- larvae consuming EPS;

- larvae consuming PSp;

Experiment conditions were as follows: constant temperature $28^{\circ} \mathrm{C}+/-1^{\circ} \mathrm{C}$, and humidity $78-80 \%$. All materials used were weighed in the $1^{\text {st }}, 21^{\text {st }}$ and $30^{\text {th }}$ day of experiment in order to assess the mass loss. The complete duration of the experiment was 30 days.

\section{Biochemical analyses}

At the end of experiment larvae were homogenized using mortar and pestle with ice-cold $0.1 \mathrm{M}$ phosphate buffer $\mathrm{pH} 7.4,1 \mathrm{mM}$ EDTA $(1: 10 \mathrm{w} / \mathrm{v})$. For total sugars aliquots of homogenates were taken and analyzed with anthrone reagent [7]. Required aliquots for total lipid assay were treated with chloroform: methanol $(1: 2 \mathrm{v} / \mathrm{v})$ and analyzed with vanillin reagent [8]. The rest of homogenate were centrifuged at $11000 \times \mathrm{g}(5 \mathrm{~min})$ and in order to assess the soluble protein content Bradford method was assayed [9].

\section{Genomic DNA Extraction}

Dissected guts from five larvae were immediately immersed in TE (10mM TRIS-HCl, pH 8.3, 0,1mM EDTA) buffer and homogenized together with glass beads. Homogenates were the source of genomic DNA obtained in enzymatic lysis with proteinase $\mathrm{K}$ and 
purified on columns GeneMATRIX Bacterial \& Yeast Genomic DNA Purification Kit (EURx, Poland) according to manufacturer protocol. These DNA were used as template in touchdown PCR.

\section{PCR amplification and DGGE analysis}

The specific V3 region of bacterial 16S rRNA gene was amplified using a set of primers. The sequences of primers are: primer 1: 5'-CGCCCGCCGCGCGCGGCGGGCGG GGC GGGGGCACGGGGGGCCTACGGGAGGCAGCAG-3' and primer 2: 5'-ATTACCGCG GCTGCTGG-3' [10]. PCR amplification was performed with Mastercycler Nexus Gradient Thermal Cycler (Eppendorf AG, Germany) as follows: $1 \mu \mathrm{l}$ of template DNA, $25 \mathrm{mM} \mathrm{MgCl}_{2}, 200 \mu \mathrm{M}$ of each dNTP's, 50 pmol of each primer and $0.2 \mathrm{U}$ of Bio-X-Act Short DNA Polymerase (Bioline, UK). The touchdown PCR protocol was: initial denaturation $94^{\circ} \mathrm{C}$ for $2 \mathrm{~min}, 20$ cycles $\left(1 \mathrm{~min}\right.$ at $94^{\circ} \mathrm{C}$, annealing temperature from $65^{\circ} \mathrm{C}$ to $56^{\circ} \mathrm{C}$ decreased by $1^{\circ} \mathrm{C}$ every $10 \mathrm{sec} ; 1 \mathrm{~min}$ at $\left.72^{\circ} \mathrm{C}\right), 10$ cycles $\left(1 \mathrm{~min}\right.$ at $94^{\circ} \mathrm{C}, 1 \mathrm{~min}$ at $55^{\circ} \mathrm{C}, 1 \mathrm{~min}$ at $72^{\circ} \mathrm{C}$ ), $7 \mathrm{~min}$ at $72^{\circ} \mathrm{C}$. Amplification product were analyzed first in $2 \%$ agarose gel electrophoresis in 1x TBE (10mM TRIS-borate, $\mathrm{pH} 8.3,1 \mathrm{mM}$ EDTA) and by ethidium bromide staining.

PCR products were separated in DGGE in $8 \%$ polyacryloamide gel using DGEEK-2001-220 system (C.B.S. Scientific, USA) for $1 \mathrm{~h}$ at $50 \mathrm{~V}$ followed by $10 \mathrm{~h}$ at $90 \mathrm{~V}$ at $60^{\circ} \mathrm{C}$ with $1 \mathrm{x}$ TAE $(10 \mathrm{mM}$ TRIS-acetate, $\mathrm{pH} 8.3,1 \mathrm{mM}$ EDTA) buffer. The denaturants (urea and formamide) range was from $40 \%$ to $58 \%$ [11]. The gel was stained with $0.1 \%$ ethidium bromide and documented in BioVision system.

All statistical analyses were performed in Statistica ${ }^{\circledR}$ software package. Differences in total contents of protein, sugars and lipids for all types of materials with the duration of exposure were tested for each factor using analysis of variance (ANOVA).

\section{Results}

\subsection{Characterisation of the material}

As the four materials intended for experiment were of different origin some significant differences in their physical properties were supposed to occur. The first test applied was melt flow ratio which could give an insight into differences in molecular structure. As it presented on the Fig. 1 the sample with the lowest value of MFR is PSp whereas EPS and PS reveal higher (2,5 times) and comparable values. As it was expected, recycling process further increased (of about 50\%) MFR value (PSr)

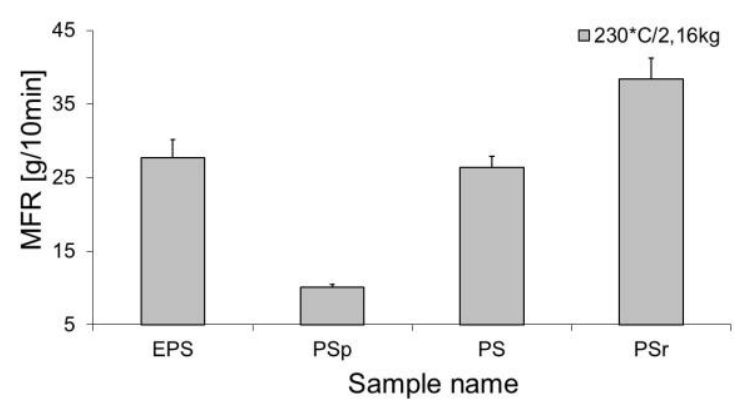

Fig. 1. MFR dependency for all investigated samples. 
Also hardness and gloss (Fig. 2) measurements gave predictable results, qualitative score is consistent with the quantitative observation: two samples with the highest value are PS and PSr whereas EPS showed the lowest one.
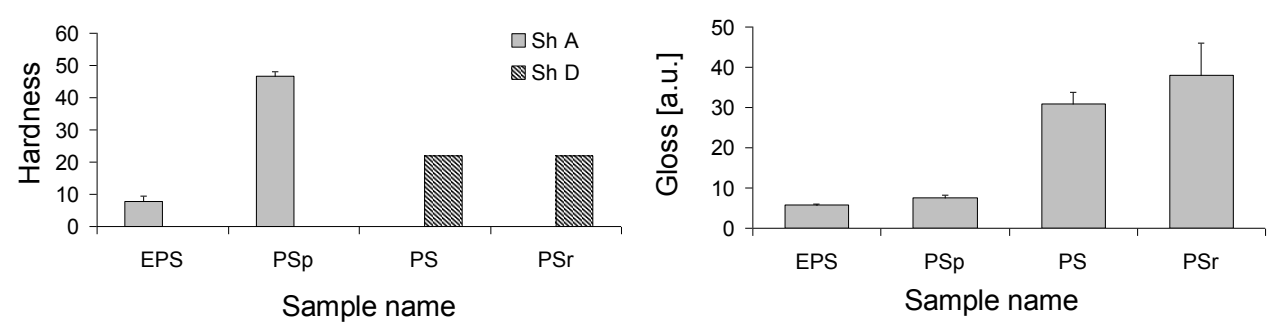

Fig. 2. Shore hardness and gloss results.

\subsection{Mass loss measurements}

The highest mass loss of studied variants was observed for building waste EPS (19.29\% at the end of experiment) and for the food package PSp (16.92\% at the end of experiment) (Table 1).

Table 1. Mass loss of materials used in studies $(\mathrm{g})$.

\begin{tabular}{|c|c|c|c|c|c|}
\hline $\begin{array}{c}\text { Type of } \\
\text { material }\end{array}$ & $\begin{array}{c}\text { Mass in the } \\
1^{\text {st }} \text { day of } \\
\text { experiment } \\
(\mathrm{g})\end{array}$ & $\begin{array}{c}\text { Mass in the } \\
21^{\text {st }} \text { day of } \\
\text { experiment } \\
(\mathrm{g})\end{array}$ & $\begin{array}{c}\text { Mass in the } \\
30^{\text {th }} \text { day of } \\
\text { experiment } \\
(\text { final })(\mathrm{g})\end{array}$ & $\begin{array}{c}\text { Mass loss } \\
(\%) \text { in } \\
21^{\text {st }} \text { day of } \\
\text { experiment }\end{array}$ & $\begin{array}{c}\text { Mass loss (\%) } \\
\text { in } \\
30^{\text {th }} \text { day of } \\
\text { experiment }\end{array}$ \\
\hline PS & 1.596 & 1.578 & 1.572 & 1.12 & $\mathbf{1 . 4 8}$ \\
\hline PSr & 1.47 & 1.392 & 1.385 & 5.29 & $\mathbf{5 . 7 5}$ \\
\hline PSp & 1.12 & 0.944 & 0.93 & 15.65 & $\mathbf{1 6 . 9 2}$ \\
\hline EPS & 0.724 & 0.608 & 0.584 & 15.97 & $\mathbf{1 9 . 2 9}$ \\
\hline
\end{tabular}

\subsection{Biochemical characteristic of mealworms}

The concentration of total protein in the body mealworms fed various polystyrene materials at the end of experiment was only slightly lower than the content of protein in control mealworms fed oatmeal (Fig 3). Thus, the concentration of protein remained relatively stable and independent on type of food provided. The total sugars content decreased up to $32.5 \%$ of its control value and the sugars level was significantly different $(\mathrm{P}<0.05)$ from control values (Fig. 4). The lowest value was obtained for mealworms fed PSr and PS. The total lipids content decreased up to $45 \%$ of its control value and it was significantly different $(\mathrm{P}<0.05)$ from control values (Fig. 5). The lowest value was obtained for PS, then PSr. 


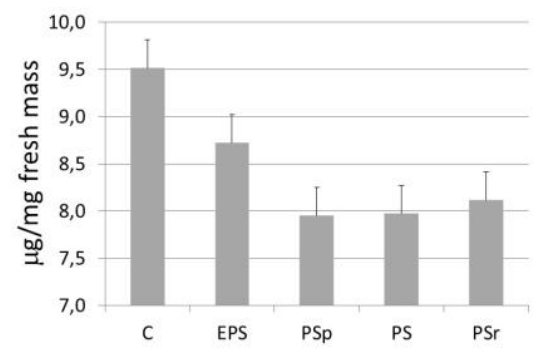

Fig. 3. Protein in larvae fed various polystyrene materials ( $\mu \mathrm{g} / \mathrm{mg}$ of fresh mass).

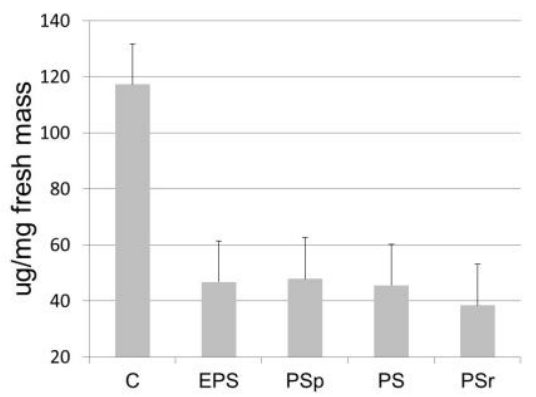

Fig. 4. Sugars in larvae fed various polystyrene materials ( $\mu \mathrm{g} / \mathrm{mg}$ of fresh mass).

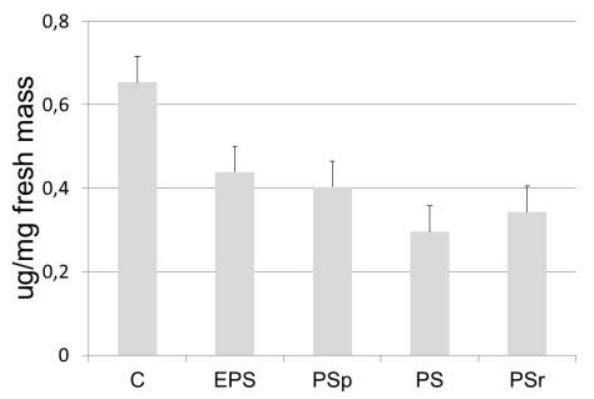

Fig. 5. Total lipids in larvae fed various polystyrene materials ( $\mu \mathrm{g} / \mathrm{mg}$ of fresh mass).

\subsection{Denaturing gradient gel electrophoresis}

The DGGE analysis showed the differences in structure of gut microbiome depending on type of food served to mealworms. The presence of four bands 1-4 (Fig 6), which are not identified in the control, corresponds to four species of bacteria which could be probably engaged in polystyrene biodegradation. Widely different pattern on lane $\mathrm{C}$ - mealworms fed PS (raw polystyrene) is incomparable to the pattern of other samples. It could be a result of insufficient amount of food for microbiome adaptation as we observed the lowest loss mass of this material, $1.48 \%$ only (Table 1). 


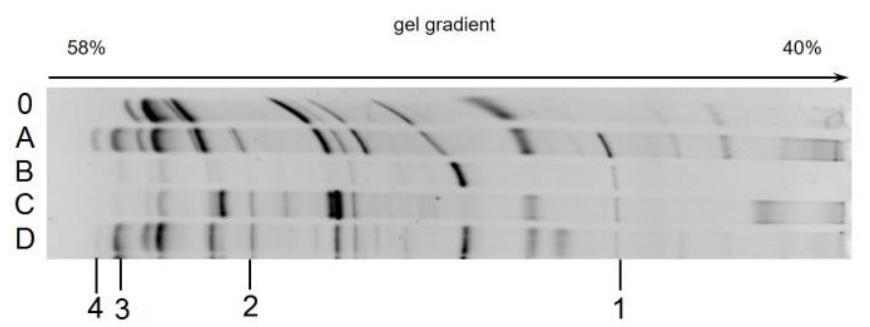

Fig. 6. DGGE gel with denaturant gradient $40-58 \%$ amplified in PCR bacterial DNA from gut of larvae fed various polystyrene materials. Lane 0 -control, lane A - EPS, lane B - PSp, lane C - PS, lane D - PSr. 1,2,3 and 4- bands corresponding to bacterial strains presented in gut of larvae fed polystyrene but not present in guts of control population.

\section{Discussion}

The characteristic of the material used (PS, PSr, EPS, PSp) was important in term of its availability to mealworms. The most preferable was EPS as the mass loss was the highest during the experiment. This fact was confirmed by hardness measurements in which (refer to Fig. 2) hardness increased in the EPS $<$ PSp $<$ PS $<$ PSr series. This observation is consistent with the mass loss measurement, especially when error bars are taken into consideration. Also, gloss measurement (giving back the information concerning the physical condition of the surface) is consistent with the previous observations; the more glossy surface is the less available for the mealworms for the attack. Contrarily, the raw PS and PSr were the least accessible for mealworms which suggests the form of polystyrene is important as it can be more or less digested by larvae. The results concerning the metabolic response to different food types are in line with the obtained results of mass loss of studied PS species. The most important changes are observed in the levels of lipids, they decreased greatly in mealworms fed PS and PSr suggesting the starvation process might occur as the PS and PSr were nearly not accessible for consumption. The most common source of energy in insects during starvation is the oxidation of fatty acids stored in the form of triglyceride [12] thus, high depletion of lipids suggests its consumption during the starvation period. In this study, levels of total sugars were also affected by the food accessibility. The decrease of sugars was observed again in mealworms fed PS and PSr. Sugars are extremely important for sustaining organs especially for the nervous system [12] although, when the low levels of lipids in the body is achieved the insect has to switch to the use of carbohydrates, which is the case in our experiment. The protein levels are not significantly affected by the food type, although some authors suggest that protein synthesis also decreases during food deprivation [13]. Recent years research evidenced that host diet [14] and some environmental factors change [14] the structure of insect gut bacterial communities. In this work we showed connection between biodiversity of gut microbiota of T. molitor larvae and type and formula of consumed food material. Results of studies on biodegradation polystyrene [4] implicate changes in gut microbiota structure. In our research we obtain genomic DNA by homogenization and enzymatic lysis of whole guts to limit oxygenation to provide DNA of anaerobic and aerobic strains. The DGGE analysis showed predicted changes in set of gut bacteria which are adapted to different types of polystyrene as only source of food. MFR investigation was applied to check if there exist a consistency between polymer chain length (which is reflected in MFR value) and availability of the materials to worm larvae. As it is seen on the Fig. 1 recycling increases of about $50 \%$ MFR (compare bars respective to PS and PSr samples) what is common for such operation. PS used for the study was intended for extrusion and press moulding 
purposes. The value stays in good agreement with the manufacturers declaration. On the other hand, the material which was used to made thermoformed packaging revealed the lowest MFR value and EPS about 250\% higher and comparative to PS.As the MFR results stay in agreement with the state of the art, they are inconsistent with the other presented. The withdrawn conclusion is that chain length does not affect the mass loss ratio thus has no significant influence on the material consumption.

\section{Conclusions}

To summarise, although previous studies suggested the possibility of biodegradation of polystyrene, not all kinds of this material are bioavailable to the same extent for mealworms. Some of them are ready to consumption such as EPS (expanded) and PSp (packaging material for food products) and the rate of biodegradation is quite efficient, other like raw PS and PSr (processed) are difficult for chewing which is with line with their characteristic (hardness and gloss). It has been proved that metabolic response to different types of food delivered was adequate to the loss of mass of studies polystyrene forms. What is more, during DGGE analysis we identified 4 additional bands in the gut of $T$. molitor fed polystyrene corresponding to bacteria which could be probably responsible for the biodegradation of this material as they are absent in the gut of control mealworms. The changes in gut biodiversity even in starved mealworms need further studies.

The work was realized within the allocation No. 0401/0068/16 awarded for Faculty of Environmental Engineering Wroclaw University of Science and Technology by Ministry of Science and Higher Education.

\section{References}

1. H.K. Webb, J. Arnott, R.J. Crawford, E.P. Ivanova, Polymers 5, 1 (2013)

2. T. Faravelli, M. Pinciroli, F. Pisano, G. Bozzano, M. Dente, E. Ranzi, J. Anal. Appl. Pyrolysis 60, 103 (2001)

3. H.A. Pushpadass, R.W. Weber, J.J. Dumais, M.A. Hanna, Bioresource Technol. 101, 7258 (2010)

4. Y. Yang, J. Yang, W.-M. Wu, J. Zhao, Y. Song, L. Gao, R. Yang, L. Jiang, Environ. Sci. Technol. 49, 6 (2015)

5. J. Hardouin, G. Mahoux, Zootechnie d'insectes (BEDIM, Gembloux, Belgique, 2003)

6. https://synthosgroup.com/files/user/ifs/tds_synthos_ps_gp_137_en.pdf - access date 2017-03-20

7. E. Van Handel, JAMCA 1, 1 (1985)

8. E. Van Handel, JAMCA 1, 2 (1985)

9. Bradford, Anal. Biochem. 72, 6 (1976)

10. G. Muyzer, E.C. De Waal, A.G. Uitterlinden, Appl. Environ. Microbiol. 59, 3 (1993)

11. Y. Wang, Y. Zhang, Ann. Entomol. Soc. Am. 108, 941 (2015)

12. D. Renault, F. Hervant, P. Vernon, Phys. Entomol. 27, 291 (2002)

13. G. Bosquet Comp. Biochem. Phys. 58, 377 (1977)

14. J. Jung, A. Heo, Y.W. Park, Y.J Kim, H. Koh, W. Park. J. Microbiol. Biotechnol. 24, 7 (2014)

15. D.R. Colman, E.C. Toolson, C.D. Takacs-Vesbach, Mol. Ecol. 21 (2012) 